\title{
X-Ray Photoemission Study of the Oxidation of Hafnium
}

\author{
A. R. Chourasia, ${ }^{1}$ J. L. Hickman, ${ }^{1}$ R. L. Miller, ${ }^{1}$ G. A. Nixon, ${ }^{1}$ and M. A. Seabolt ${ }^{2}$ \\ ${ }^{1}$ Department of Physics, Texas A\&M University-Commerce, Commerce, TX 75429, USA \\ ${ }^{2} 8416$ FM 904, Pecan Gap, TX 75469, USA
}

Correspondence should be addressed to A. R. Chourasia, anil_chourasia@tamu-commerce.edu

Received 6 August 2008; Accepted 18 October 2008

Recommended by Jin Zhang

About $20 \AA$ of hafnium were deposited on silicon substrates using the electron beam evaporation technique. Two types of samples were investigated. In one type, the substrate was kept at the ambient temperature. After the deposition, the substrate temperature was increased to 100,200 , and $300^{\circ} \mathrm{C}$. In the other type, the substrate temperature was held fixed at some value during the deposition. For this type, the substrate temperatures used were 100, 200, 300, 400, 500, 550, and $600^{\circ} \mathrm{C}$. The samples were characterized in situ by the technique of X-ray photoelectron spectroscopy. No trace of elemental hafnium is observed in the deposited overlayer. Also, there is no evidence of any chemical reactivity between the overlayer and the silicon substrate over the temperature range used. The hafnium overlayer shows a mixture of the dioxide and the suboxide. The ratio of the suboxide to dioxide is observed to be more in the first type of samples. The spectral data indicate that hafnium has a strong affinity for oxygen. The overlayer gets completely oxidized to form $\mathrm{HfO}_{2}$ at substrate temperature around $300^{\circ} \mathrm{C}$ for the first type of samples and at substrate temperature greater than $550^{\circ} \mathrm{C}$ for the second type.

Copyright (C 2009 A. R. Chourasia et al. This is an open access article distributed under the Creative Commons Attribution License, which permits unrestricted use, distribution, and reproduction in any medium, provided the original work is properly cited.

\section{Introduction}

In the semiconductor industry, the success of metal-oxidesemiconductor structures depends largely on the "near perfect" $\mathrm{SiO}_{2} / \mathrm{Si}$ interface. With the continued downscaling of complementary MOS (CMOS) devices, $\mathrm{SiO}_{2}$ seems to have reached its limits. As the MOS devices are scaled down to the $65 \mathrm{~nm}$ technology mode (physical gate length equal to $45 \mathrm{~nm}$ ), the thickness of the gate dielectric needs to be less than $2 \mathrm{~nm}[1,2]$. In this regime, the major concerns are related to dramatic increase in direct tunneling leakage current and reliability issues associated with the $\mathrm{SiO}_{2}$ films [3]. The only alternative is to increase the dielectric constant of the gate dielectric. Hafnium dioxide $\left(\mathrm{HfO}_{2}\right)$ is emerging as a high $\kappa$ dielectric substitute for $\mathrm{SiO}_{2}$ because of its large band gap, high $\kappa$ and good thermodynamic stability on Si [4], compatibility with complimentary metal oxide semiconductor processing, and good reliability [5].

Investigation of $\mathrm{HfO}_{2}$-Si systems has been focused on the direct deposition of $\mathrm{HfO}_{2}$ thin films on silicon substrate using different deposition techniques: atomic layer deposition [2,6], chemical deposition [7], reactive $\mathrm{dc}$ magnetron sputtering $[4,8]$, chemical vapor deposition [9], and e-beam technique [10]. Very few studies have been performed involving evaporation of elemental hafnium. Xing et al. [11] have deposited elemental hafnium on silicon and investigated the Hf/Si interface. Suzer et al. [12] have studied the oxidation of elemental hafnium using soft Xray photoemission spectroscopy (XPS). Morant et al. [13] have studied the initial oxidation of hafnium foil by XPS. It has been observed that hafnium suboxide is formed in addition to the hafnium dioxide $[9,12,13]$. The formation of the suboxide depends on the substrate temperature and the depositing conditions. To our knowledge, no systematic investigation on the formation of hafnium suboxide and hafnium dioxide as a function of depositing conditions has been carried out.

In this investigation, we have studied the formation of hafnium dioxide and hafnium suboxide as a function of the substrate temperature. The technique of XPS has been employed for in situ characterization of the samples. The formation of the suboxide and the dioxide has been compared in two types of samples. One type consists of depositing the hafnium film at room temperature followed 
by annealing. In the other type, the substrate was brought to the desired temperature before the deposition. The results show a systematic variation in the content of the suboxide and the dioxide in these samples. The formation of the dioxide and the suboxide indicates that hafnium has a strong affinity for oxygen.

\section{Experiment}

Hafnium wires (2 mm diameter) of 96.7\% (Alfa Aesar, Mass, USA) were used in this work. The sample contained nominal $3 \% \mathrm{Zr}$ as impurity according to the supplier. The silicon substrates (100; p-type) used in the present investigation were cleaned with HF to get rid of any native oxide that might be present on the surface. Hafnium films with estimated thickness of $20 \AA$ were deposited on silicon substrates. The thickness of the deposited films was calibrated using a quartz crystal oscillator. The deposition was carried out by the electron beam technique. The EGN4 electron gun (Oxford Applied Research, Oxfordshire, UK) was used for the deposition. Four samples in the form of wires can be mounted onto this gun. The sample to be deposited can be selected by selecting the appropriate filament. Two types of samples were investigated. For one type (labeled as type A), the substrate was kept at the ambient temperature during the deposition. After the deposition, the temperature of the sample+overlayer was raised to the desired value and held at that temperature for 30 minutes. For this type, the substrate temperatures used were room temperature (as-deposited), 100,200 , and $300^{\circ} \mathrm{C}$. In the other type (labeled as type B), the substrate was brought to the desired temperature prior to the deposition. After the deposition, the sample was held at that temperature for 30 minutes. The substrate temperatures used for this type of samples were 100, 200, 300, 400, 500, 550, and $600^{\circ} \mathrm{C}$. The base pressure before deposition was high $10^{-9}$ torr and rose to low $10^{-8}$ torr during the deposition. The deposition chamber is connected to the analysis chamber. The overlayers were characterized in situ by XPS.

Physical Electronics PHI 5100 ESCA system was used in the present investigation. The magnesium anode (energy = $1253.6 \mathrm{eV}$ ) was used as the source of excitation. For calibration purposes, pure silver, gold, and copper samples were used. The $\mathrm{Cu} 2 \mathrm{p}_{3 / 2}$ and $\mathrm{Au} 4 \mathrm{f}_{7 / 2}$ lines were set to give a binding energy (BE) difference of $848.6 \mathrm{eV}$. This established the linearity of the $\mathrm{BE}$ scale. The $\mathrm{Ag} 3 \mathrm{~d}_{5 / 2}$ line was set at $368.2 \mathrm{eV}$, the $\mathrm{Cu} 2 \mathrm{p}_{3 / 2}$ line at $932.6 \mathrm{eV}$, and the $\mathrm{Au} 4 \mathrm{f}_{7 / 2}$ line at $84.0 \mathrm{eV}$. The full width at half maximum (FWHM) of the Ag $3 \mathrm{~d}_{5 / 2}$ peak was determined to be $1.8 \mathrm{eV}$ which gives a measure of the resolution. The base pressure during analysis was $<10^{-9}$ torr. The survey spectra were taken with pass energy of $89.45 \mathrm{eV}$, and the multiplex spectra were taken with $35.75 \mathrm{eV}$ pass energy.

\section{Results and Discussion}

The multiplex spectra in the hafnium $4 \mathrm{f}$ and oxygen $1 \mathrm{~s}$ regions were recorded in the samples. The hafnium $4 \mathrm{~s}$ peak has a BE of $\sim 537 \mathrm{eV}$ and thus overlaps (see, e.g., [14]) with the oxygen 1 s region (around $535 \mathrm{eV}$ ). The

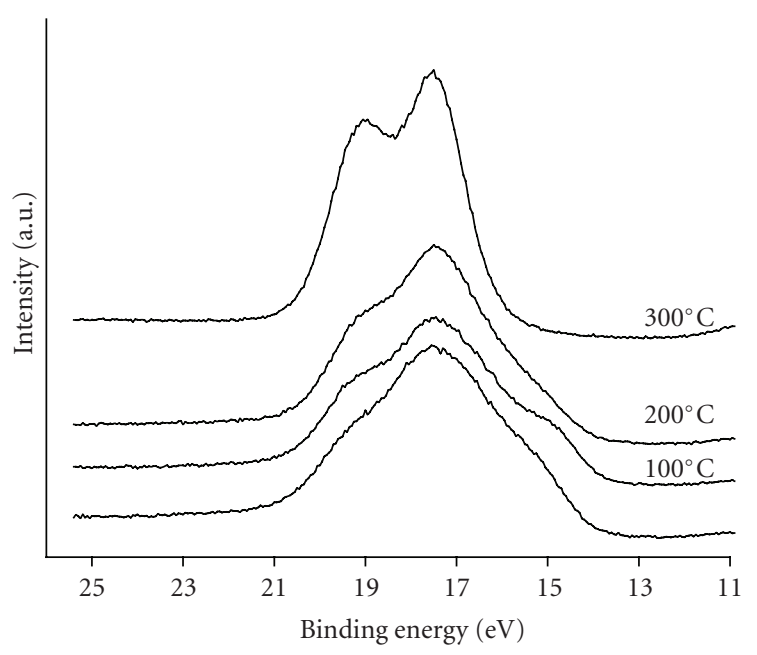

FIGURE 1: Normalized Hf $4 \mathrm{f}$ spectra in type A samples as a function of substrate temperature. The major peaks have been aligned.

analyses were, therefore, confined to the Hf $4 \mathrm{f}$ region. In the spectra recorded for all the samples, a shoulder is observed on the low BE side of the main peak in the $\mathrm{Hf} 4 \mathrm{f}$ region. Investigation of the silicon $2 \mathrm{p}$ region did not show any significant changes in shape and binding energy. The shoulder, therefore, does not correspond to any chemical interaction between the deposited hafnium overlayer and the silicon substrate under the deposition conditions used in the present investigation.

Figure 1 shows the multiplex spectra in the Hf $4 \mathrm{f}$ region for type A samples for the various temperatures. The multiplex spectra recorded in oxygen $1 \mathrm{~s}$ region in these samples are shown in Figure 2. The spectra represent the average of thirty runs taken to reduce the statistical noise and thus to improve the signal-to-noise ratio. The Hf $4 \mathrm{f}$ spectra have been normalized to have equal intensity at $12.0 \mathrm{eV}$, and the oxygen 1s spectra have been normalized to have equal intensity at $527.0 \mathrm{eV}$. The major peak in spectra has been aligned for comparison purposes. In Figure 2, a shoulder is observed on the high BE side of the main peak in the oxygen 1 s region. This is due to the Hf 4 s core peak. This confirmed by the fact that this shoulder exists even when the hafnium overlayer is completely oxidized (spectrum corresponding to $300^{\circ} \mathrm{C}$ in Figure 2).

The BE difference between the $\mathrm{Hf}_{4 \mathrm{f}_{7 / 2}}$ levels in elemental $\mathrm{Hf}$ and in the dioxide has been determined to be $3.6 \mathrm{eV}$ $[12,15]$. Since BE difference between the main peak and the shoulder is less than this value $(\sim 1.7 \mathrm{eV})$, the spectra indicate no presence of metallic hafnium. The main peak is due to the formation of the hafnium dioxide as the elemental film gets deposited on the substrate. The presence of the shoulder is, therefore, interpreted as the formation of Hf suboxide. A slight increase in the intensity of the shoulder is observed as the temperature is increased to $200^{\circ} \mathrm{C}$. At temperatures higher than $200^{\circ} \mathrm{C}$, the intensity decreases and the shoulder is seen to disappear at a temperature of $300^{\circ} \mathrm{C}$. The spectrum of the sample at this temperature shows the presence of two peaks corresponding to the $4 \mathrm{f}_{7 / 2}$ and $4 \mathrm{f}_{5 / 2}$ levels of hafnium 


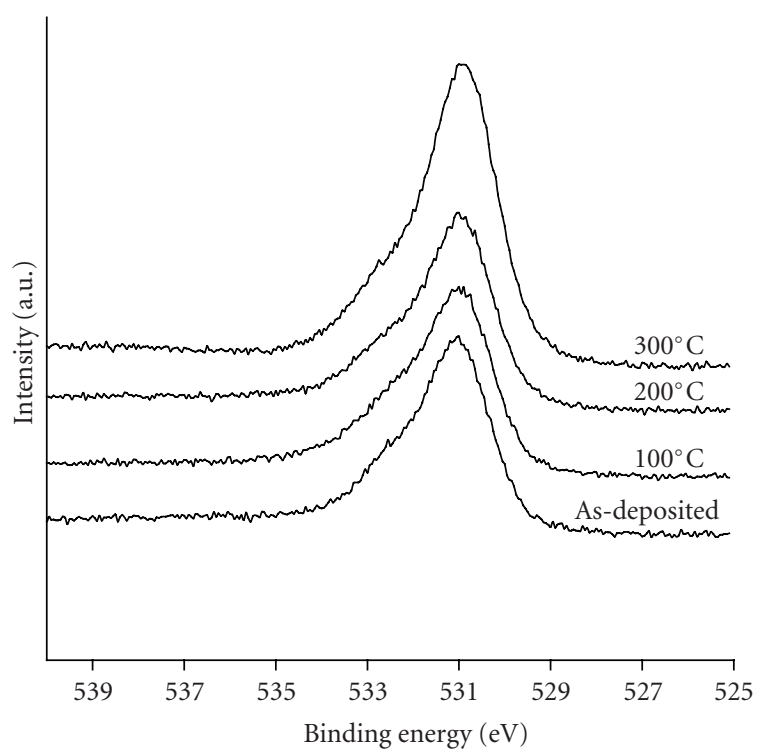

Figure 2: Normalized oxygen 1s spectra in type A samples as a function of substrate temperature. The major peaks have been aligned.

in hafnium dioxide. This is further corroborated by the $\mathrm{BE}$ difference explained later. Our data, therefore, show that in this type of samples, the presence of suboxide is detected in addition to the dioxide. The suboxide exists till $200^{\circ} \mathrm{C}$. At temperatures around $300^{\circ} \mathrm{C}$, the overlayer is completely oxidized to form $\mathrm{HfO}_{2}$.

To determine the amount of the dioxide and the suboxide present in the samples, the spectra in the $4 \mathrm{f}$ region were fitted with four curves corresponding to the $4 \mathrm{f}_{7 / 2}$ and $4 \mathrm{f}_{5 / 2}$ levels in the dioxide and in the suboxide. During the curve fitting, the ratio of the areas of the peaks was kept fixed at the statistical ratio 1.4, the FWHM for the dioxide at $2.1 \mathrm{eV}$, and that for the suboxide of $4 \mathrm{f}_{7 / 2}$ level at $1.3 \mathrm{eV}$. The separation between the $4 \mathrm{f}_{7 / 2}$ and $4 \mathrm{f}_{5 / 2}$ peaks was locked at the value of $1.7 \mathrm{eV}$. A combination of Gaussian-Lorentzian was used with about $80 \%$ Gaussian. These parameters have been taken from our earlier study [15] and from $[12,13]$. An example of curve fitting is shown in Figure 3 for the sample with substrate temperature $100^{\circ} \mathrm{C}$. The areas under the $4 \mathrm{f}_{7 / 2}$ peak for both the dioxide and the suboxide were determined from such a curve fitting. The areas were normalized against the total area and are plotted in Figure 4. The suboxide peak clearly shows an initial increase as compared to the as-deposited sample. It is found to remain nearly constant for the 100 and $200^{\circ} \mathrm{C}$ samples and is found to disappear for the $300^{\circ} \mathrm{C}$ sample. The dioxide peak shows an initial decrease as compared to the as-deposited sample and remains approximately constant for the 100 and $200^{\circ} \mathrm{C}$ samples. The data, therefore, show the presence of hafnium suboxide in this type of sample till the substrate temperature of $200^{\circ} \mathrm{C}$. For temperatures around $300^{\circ} \mathrm{C}$, the suboxide disappears and the hafnium overlayer undergoes complete oxidation to form $\mathrm{HfO}_{2}$.

Figure 5 shows the multiplex spectra in the $\mathrm{Hf} 4 \mathrm{f}$ region for type B samples as a function of temperature. The

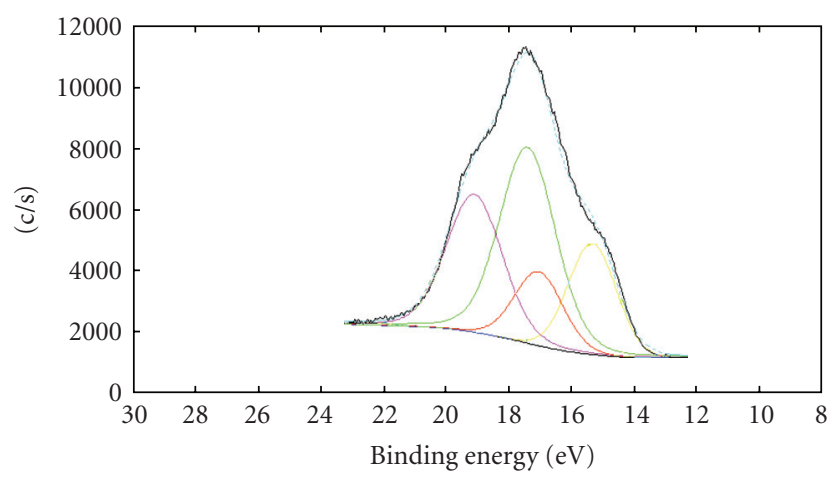

Figure 3: Curve fitting of Hf $4 \mathrm{f}$ region in type A sample with substrate temperature of $100^{\circ} \mathrm{C}$. The peaks correspond to $4 \mathrm{f}_{7 / 2}$ and $4 \mathrm{f}_{5 / 2}$ levels in the dioxide and in the suboxide. The dashed curve shows the fit.

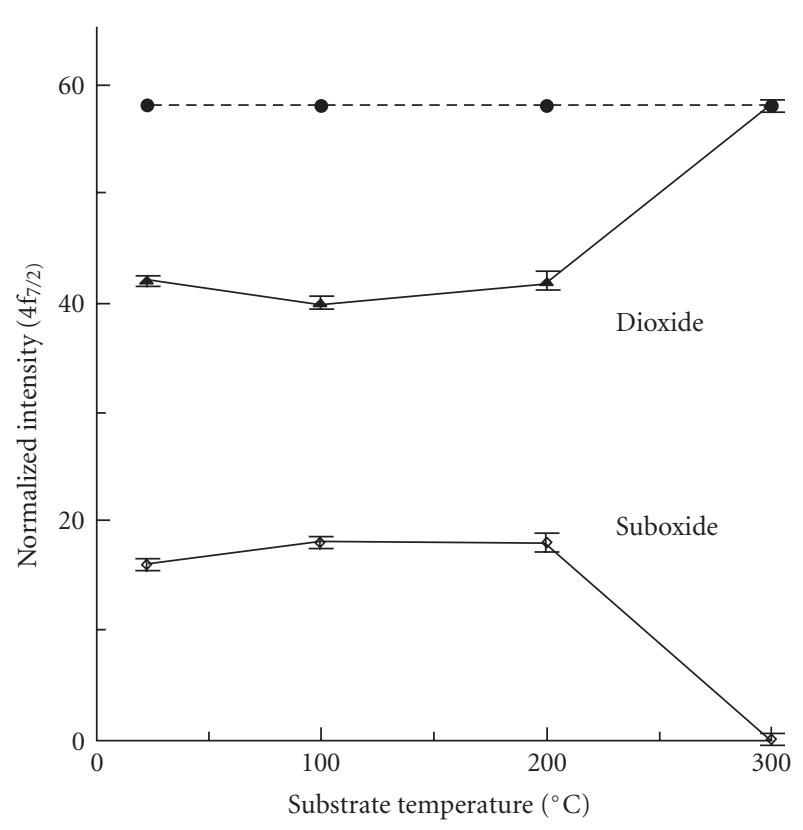

FIgure 4: Normalized intensity (in percentage) of the $4 \mathrm{f}_{7 / 2}$ peak in the dioxide and the suboxide for type A samples as a function of the substrate temperature. The areas were determined from curve fitting. The error bars are shown. The dashed curve is the total area under the $4 \mathrm{f}_{7 / 2}$ peaks.

corresponding oxygen spectra in these samples are shown in Figure 6. Again, these spectra are normalized to have equal intensity at $12.0 \mathrm{eV}$ in the $\mathrm{Hf} 4 \mathrm{f}$ region and at $527.0 \mathrm{eV}$ in the oxygen region. The major peaks in these figures have been aligned. As seen in Figure 5, the shoulder on the righthand side of the Hf $4 \mathrm{f}$ main peak is seen to increase for the $200^{\circ} \mathrm{C}$ sample as compared to the $100^{\circ} \mathrm{C}$ sample. Some slight variation is observed in the intensity of this region as a function of the substrate temperature. The shoulder is seen to disappear completely for the sample at temperature $600^{\circ} \mathrm{C}$. To determine the temperature at which the suboxide disappears, we have taken data for the sample with substrate temperature of $550^{\circ} \mathrm{C}$. It is observed that the suboxide 


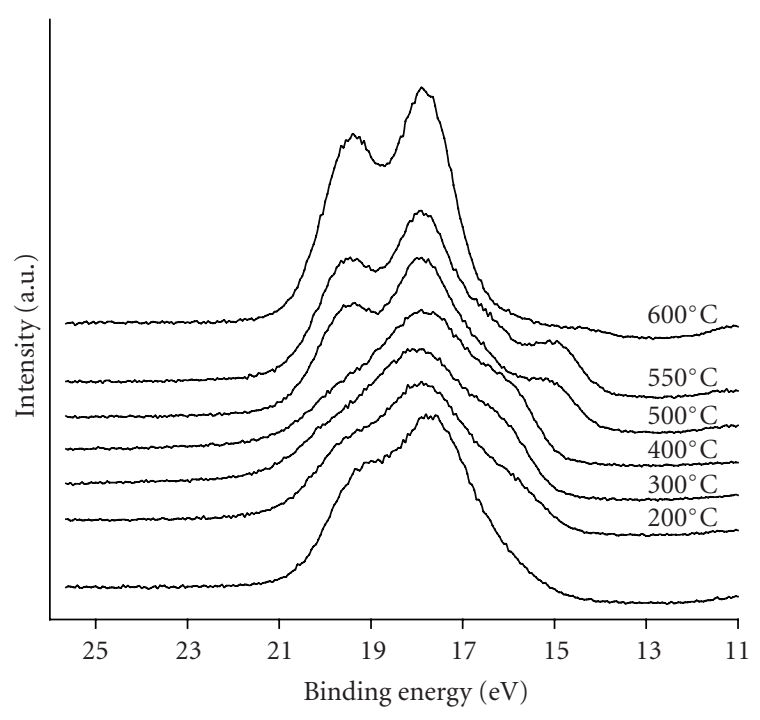

Figure 5: Normalized Hf $4 \mathrm{f}$ spectra in type B samples as a function of substrate temperature. The major peaks have been aligned.

persists even at $550^{\circ} \mathrm{C}$. The data, therefore, indicate that the suboxide in the annealed samples disappears at temperatures greater than $550^{\circ} \mathrm{C}$. The normalized areas under the $4 \mathrm{f}_{7 / 2}$ peak for the oxide and the suboxide have been determined from curve fitting the $4 \mathrm{f}$ region. The parameters used are the same as those used for type A samples. These normalized areas are plotted in Figure 7. This figure shows an initial increase in the suboxide as the temperature is increased to $200^{\circ} \mathrm{C}$. No significant variation in the content of the suboxide is observed between the temperature range from 200 to $400^{\circ} \mathrm{C}$. The concentration of the suboxide is seen to decrease at higher temperatures going to zero at $600^{\circ} \mathrm{C}$. The dioxide shows an initial decrease and is found to remain somewhat constant in the temperature range from 200 to $400^{\circ} \mathrm{C}$. At temperatures greater than $400^{\circ} \mathrm{C}$, the dioxide increases. The dashed lines in Figures 4 and 7 represent the total hafnium

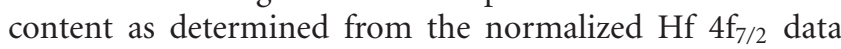
in both the dioxide and the suboxide. A comparison of the areas in these figures demonstrates that the total amount of hafnium deposited in both types of the samples remains the same. A redistribution of hafnium is observed between the dioxide and the suboxide. The content of the suboxide is seen to be more in type B samples than in type A samples. However, the dioxide content is observed to be more in type A samples than in type B samples.

Xing et al. [11] deposited about $1000 \AA$ film of elemental hafnium on silicon substrates at a base pressure of high $10^{-7}$ torr using the focused electron beam evaporation technique. The Hf/Si interface was subjected to rapid thermal oxidation process at temperatures ranging from 300 to $700^{\circ} \mathrm{C}$. They have characterized the interface using X-ray diffraction, Auger electron spectroscopy, XPS, and electrical properties. Their results indicate that at oxidation temperatures lower than $500^{\circ} \mathrm{C}$, the film is partially oxidized. The hafnium film is found to be completely transformed to $\mathrm{HfO}_{2}$ at temperatures above $500^{\circ} \mathrm{C}$. They have also observed an interfacial layer

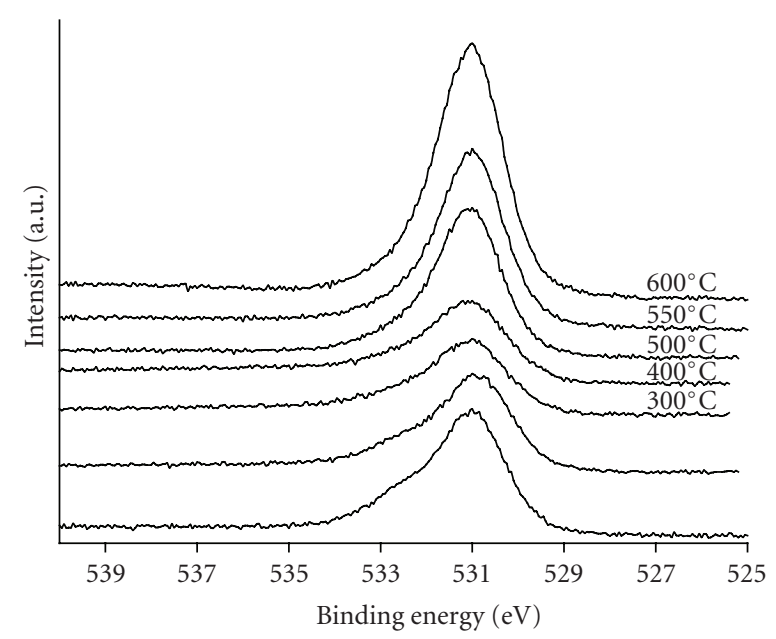

FIgure 6: Normalized oxygen 1s spectra in type B samples as a function of substrate temperature. The major peaks have been aligned.

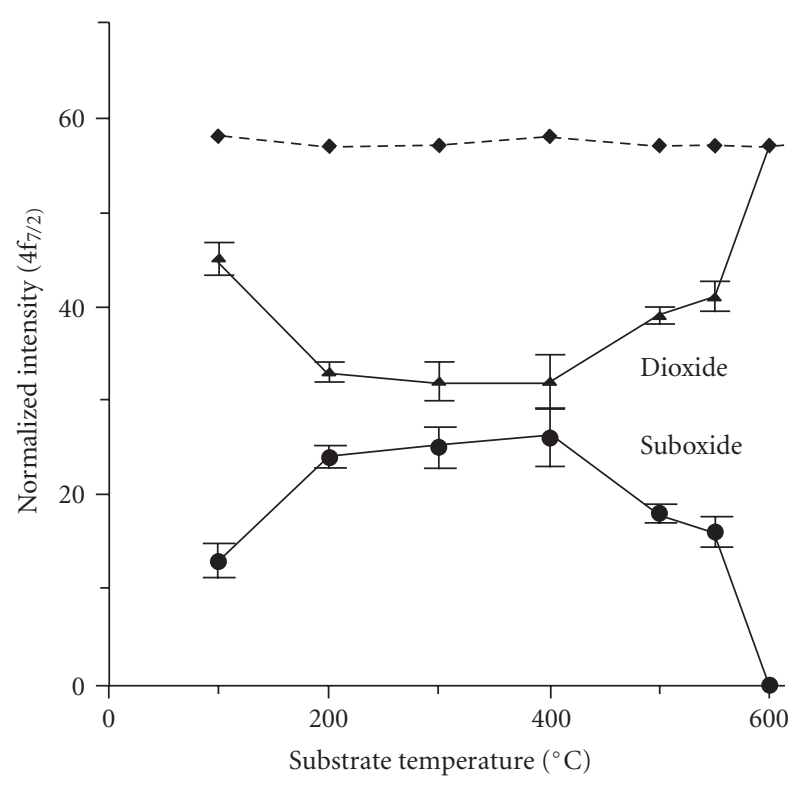

FIGURE 7: Normalized intensity (in percentage) of the $4 \mathrm{f}_{7 / 2}$ peak in the dioxide and the suboxide for type $\mathrm{B}$ samples as a function of the substrate temperature. The areas were determined from curve fitting. The error bars are shown. The dashed curve is the total area under the $4 \mathrm{f}_{7 / 2}$ peaks.

of hafnium silicate between the $\mathrm{HfO}_{2}$ and silicon substrate. No further investigation on the presence of the suboxide has been performed. In contrast to their study, our data show no chemical interaction between hafnium and silicon up to the temperature $\left(600^{\circ} \mathrm{C}\right)$ investigated in this study. This may be due to the difference in the annealing conditions performed on the samples.

Morant et al. [13] have used XPS to investigate the oxidation of $\mathrm{Hf}$ foil by exposing it to oxygen keeping the foil at room temperature. Prior to exposure, they had cleaned the sample surface by ion etching and high-temperature 
annealing. Despite the cleaning process adopted by them and with a base pressure of $<10^{-10}$ torr in the chamber, their analysis still showed the presence of some oxygen on the foil. This indicates that hafnium has a strong affinity for oxygen; consistent with our observation that hafnium gets deposited as hafnium oxide(s) at higher pressures. Upon oxygen exposures $\leq 5 \mathrm{~L}$, they observed the formation of hafnium suboxide. Hafnium dioxide was found to be formed at oxygen exposures $\geq 10 \mathrm{~L}$. In their study, no mention has been made about the charge correction to the BEs in the presence of the oxides. Their study shows that the thickness of the suboxide increases to 4 monolayers as the oxygen exposure is increased to $\sim 25 \mathrm{~L}$. This thickness then decreases to a saturation value of $\sim 4 \AA$ upon further exposure to oxygen. Their study also shows that the suboxide is present in the sample even at higher exposures of oxygen. Our data demonstrates the presence of the suboxide as a function of the substrate temperature and the complete oxidation of the overlayer at higher temperatures.

Suzer et al. [12] have utilized soft X-ray photoemission spectroscopy to determine the $\mathrm{BE}$ shifts and the valence band offsets of $\mathrm{HfO}_{2}$ grown on $\mathrm{Hf}$ metal. In their study, the polycrystalline hafnium foil was kept at a temperature of $200^{\circ} \mathrm{C}$ and was exposed to oxygen for various durations. They have observed the formation of hafnium suboxide in addition to the dioxide. The BE difference between the $4 \mathrm{f}_{7 / 2}$ peaks in the dioxide and the suboxide has been determined to be $1.7 \mathrm{eV}$. In our investigation, this difference is seen to be in the range 1.6-2.8 eV and is found to depend upon the amount of the suboxide present in the sample.

In order to get more information on the formation of the oxides, we have determined the BE difference between the main peak in the oxygen $1 \mathrm{~s}$ region and the $4 \mathrm{f}_{7 / 2}$ peak in the hafnium dioxide as well as in the suboxide. These differences are plotted in Figure 8. The dashed horizontal line in this figure corresponds to the corresponding $\mathrm{BE}$ difference value of $513.2 \mathrm{eV}$ in the pure $\mathrm{HfO}_{2}$ sample, as determined in the previous study [15]. In case of $\mathrm{HfO}_{2}$, the difference is observed to start from a slightly higher value and shows a decreasing trend as the temperature is increased in type A samples. The expected difference is seen to be reached at temperature above $200^{\circ} \mathrm{C}$. Type $\mathrm{B}$ samples show a different behavior. For these samples, the BE difference starts from a higher value and is observed to increase until about $400^{\circ} \mathrm{C}$. For temperatures greater than $400^{\circ} \mathrm{C}$, it decreases sharply reaching the expected value at about $600^{\circ} \mathrm{C}$. The data indicate that the presence of the suboxide produces different surface charging effects in the samples. The charging effect is more pronounced in type B samples (which contain more suboxide) than in type A samples. The presence of oxygen may be attributed to the chemisorbed oxygen on the hafnium wire and/or residual water vapor in the chamber.

In conclusion, we have compared the formation of the hafnium dioxide and the hafnium suboxide in two types of samples. Elemental hafnium gets deposited as a mixture of the dioxide and the suboxide. The content of the suboxide in type A samples is observed to be more than that in type B samples. The dioxide is found to be more in type B samples than in type A samples. The hafnium overlayer is observed to

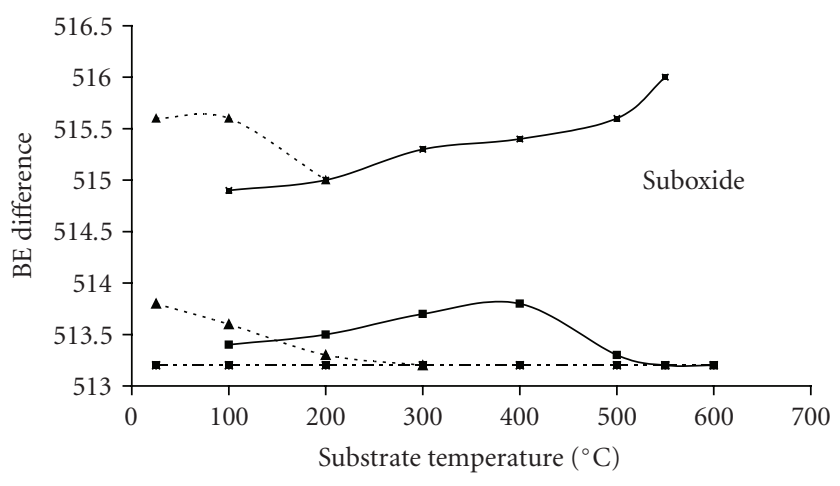

FIGURE 8: The difference in the BE between the oxygen 1s peak and the $\mathrm{Hf}_{4 \mathrm{f}} \mathrm{f}_{7 / 2}$ peak as a function of substrate temperature. The dashed curves correspond to type A samples and the solid curves to type $\mathrm{B}$ samples. The dashed-dotted horizontal line at $513.2 \mathrm{eV}$ is the $\mathrm{BE}$ difference in the pure $\mathrm{HfO}_{2}$ sample.

be completely oxidized to $\mathrm{HfO}_{2}$ at a substrate temperature of $300^{\circ} \mathrm{C}$ for type A sample and at $600^{\circ} \mathrm{C}$ for type B sample. The spectral data also show no chemical interaction between the hafnium overlayer and the underlying silicon substrate under the depositing conditions used in this investigation.

\section{Acknowledgments}

The work is supported by grants from Research Corporation and Organized Research, Texas A\&M University-Commerce. The authors would like to thank Steven McDonough for his assistance in the work.

\section{References}

[1] F. Lime, K. Oshima, M. Cassé, et al., "Carrier mobility in advanced CMOS devices with metal gate and $\mathrm{HfO}_{2}$ gate dielectric," Solid-State Electronics, vol. 47, no. 10, pp. 1617$1621,2003$.

[2] A. Deshpande, R. Inman, G. Jursich, and C. Takoudis, "Characterization of hafnium oxide grown on silicon by atomic layer deposition: interface structure," Microelectronic Engineering, vol. 83, no. 3, pp. 547-552, 2006.

[3] G. D. Wilk, R. M. Wallace, and J. M. Anthony, "High$\kappa$ gate dielectrics: current status and materials properties considerations," Journal of Applied Physics, vol. 89, no. 10, pp. 5243-5275, 2001.

[4] S.-W. Nam, J.-H. Yoo, S. Nam, et al., "Influence of annealing condition on the properties of sputtered hafnium oxide," Journal of Non-Crystalline Solids, vol. 303, no. 1, pp. 139-143, 2002.

[5] C. J. Först, C. R. Ashman, K. Schwarz, and P. E. Blöchl, "The interface between silicon and a high- $k$ oxide," Nature, vol. 427, no. 6969, pp. 53-56, 2004.

[6] V. Sammelselg, R. Rammula, J. Aarik, A. Kikas, K. Kooser, and T. Käämbre, "XPS and AFM investigation of hafnium dioxide thin films prepared by atomic layer deposition on silicon," Journal of Electron Spectroscopy and Related Phenomena, vol. 156-158, pp. 150-154, 2007. 
[7] S. Lee and D.-L. Kwong, "Dual poly-Si gate metal oxide semiconductor field effect transistors fabricated with highquality chemical vapor deposition $\mathrm{HfO}_{2}$ gate dielectrics," Japanese Journal of Applied Physics, vol. 42, no. 12, pp. 7256$7258,2003$.

[8] S. Nam, S.-W. Nam, J.-H. Yoo, and D.-H. Ko, "Interface control by modified sputtering on $\mathrm{Pt} / \mathrm{HfO}_{2} / \mathrm{Si}$ system," Materials Science and Engineering B, vol. 102, no. 1-3, pp. 123-127, 2003.

[9] T. P. Smirnova, L. V. Yakovkina, V. N. Kitchai, et al., "Chemical vapor deposition and characterization of hafnium oxide films," Journal of Physics and Chemistry of Solids, vol. 69, no. 2-3, pp. 685-687, 2008.

[10] D. Weier, C. Flüchter, A. de Siervo, et al., "Photoelectron spectroscopy (XPS) and photoelectron diffraction (XPD) studies on the system hafnium silicide and hafnium oxide on Si $\left(\begin{array}{lll}1 & 0 & 0\end{array}\right), "$ Materials Science in Semiconductor Processing, vol. 9, no. 6, pp. 1055-1060, 2006.

[11] S. Xing, N. Zhang, Z. Song, Q. Shen, and C. Lin, "Preparation of hafnium oxide thin film by electron beam evaporation of hafnium incorporating a post thermal process," Microelectronic Engineering, vol. 66, no. 1-4, pp. 451-456, 2003.

[12] S. Suzer, S. Sayan, M. M. B. Holl, E. Garfunkel, Z. Hussain, and N. M. Hamdan, "Soft X-ray photoemission studies of Hf oxidation," Journal of Vacuum Science and Technology A, vol. 21, no. 1, pp. 106-109, 2003.

[13] C. Morant, L. Galán, and J. M. Sanz, "An XPS study of the initial stages of oxidation of hafnium," Surface and Interface Analysis, vol. 16, no. 1-12, pp. 304-308, 1990.

[14] N. Ohtsu, B. Tsuchiya, M. Oku, T. Shikama, and K. Wagatsuma, "X-ray photoelectron spectroscopic study on initial oxidation of hafnium hydride fractured in an ultra-high vacuum," Applied Surface Science, vol. 253, no. 16, pp. 68446847, 2007.

[15] A. R. Chourasia and R. L. Miller, "Auger parameter of hafnium in elemental hafnium and in hafnium oxide," Surface Science, vol. 573, no. 2, pp. 320-326, 2004. 


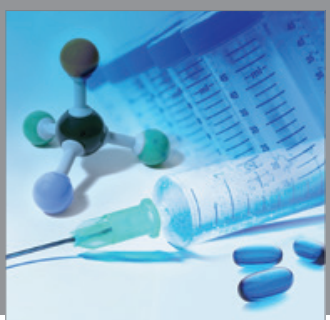

International Journal of

Medicinal Chemistry

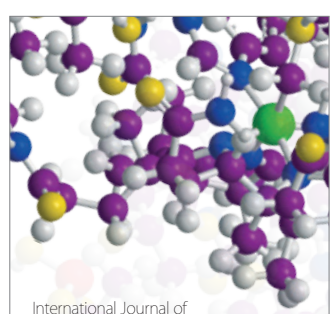

Carbohydrate Chemistry

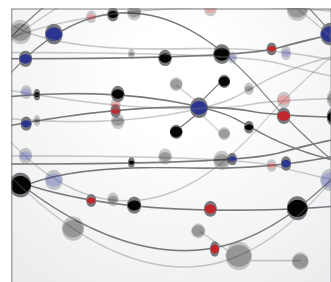

The Scientific World Journal
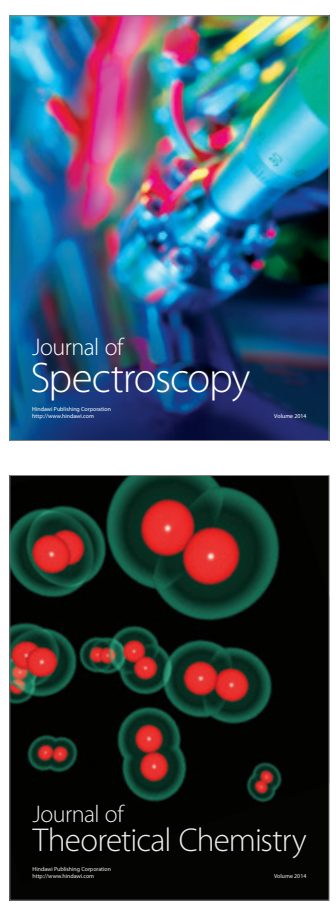
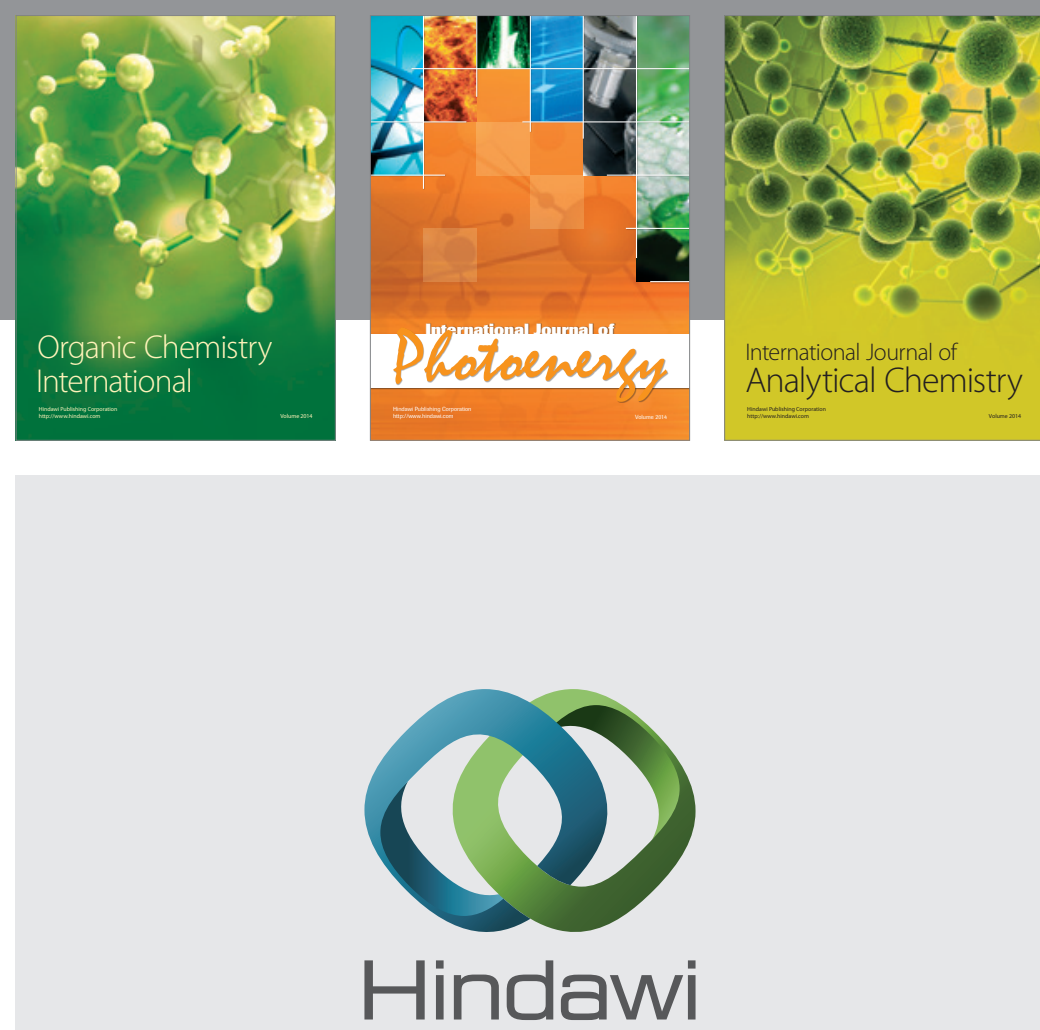

Submit your manuscripts at

http://www.hindawi.com
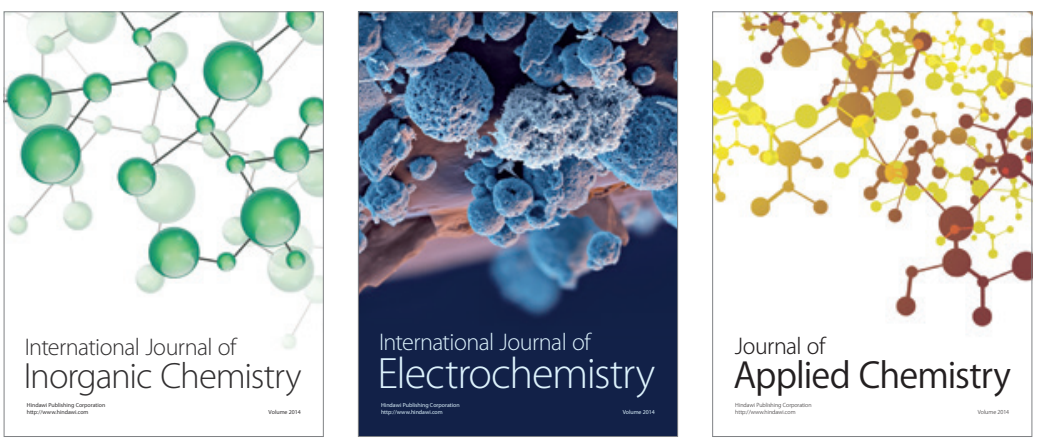

Journal of

Applied Chemistry
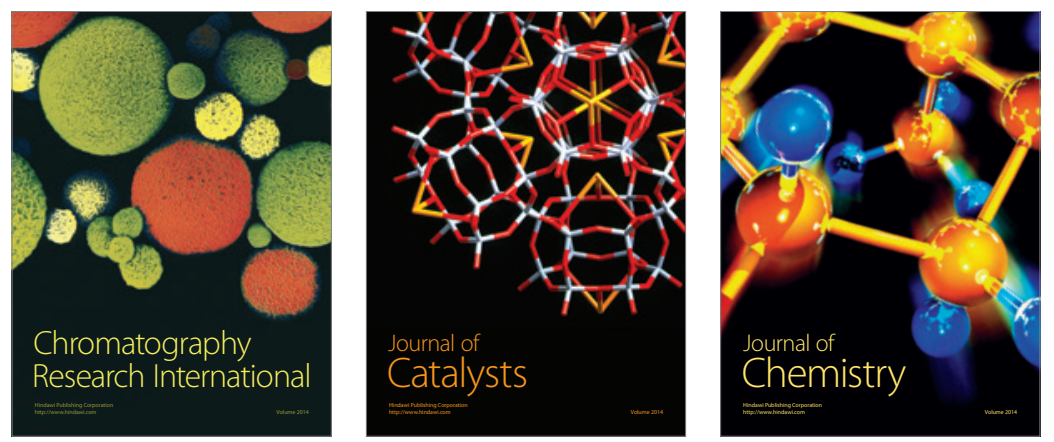
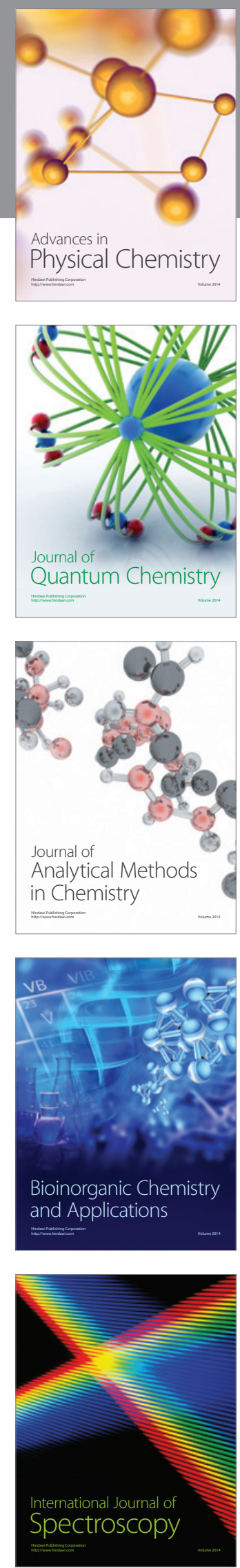